University of Nebraska - Lincoln

DigitalCommons@University of Nebraska - Lincoln

2014

\title{
Prevention of low back pain in the military cluster randomized trial: effects of brief psychosocial education on total and low back pain-related health care costs
}

John D. Childs

Keesler Air Force Base, Army Medical Department Center and School, childsjd@gmail.com

Samuel S. Wu

University of Florida

Deydre S. Teyhen

Army Medical Department Center and School, U.S. Army Medical Research and Material Command

Michael E. Robinson

University of Florida

Steven Z. George

University of Florida

Follow this and additional works at: http:// digitalcommons.unl.edu/usafresearch

Childs, John D.; Wu, Samuel S.; Teyhen, Deydre S.; Robinson, Michael E.; and George, Steven Z., "Prevention of low back pain in the military cluster randomized trial: effects of brief psychosocial education on total and low back pain-related health care costs" (2014). U.S. Air Force Research. 47.

http://digitalcommons.unl.edu/usafresearch/47 


\title{
Prevention of low back pain in the military cluster randomized trial: effects of brief psychosocial education on total and low back pain-related health care costs
}

\author{
John D. Childs, PT, PhD, MBA a,b,*, Samuel S. Wu, PhD ${ }^{\text {c }}$, Deydre S. Teyhen, PT, $\mathrm{PhD}^{\mathrm{b}, \mathrm{d}}$, \\ Michael E. Robinson, $\mathrm{PhD}^{\mathrm{e}, \mathrm{f}}$, Steven Z. George, PT, $\mathrm{PhD}^{\mathrm{e}, \mathrm{g}}$ \\ ${ }^{a}$ Department of Physical Therapy (MSGS/SGCUY), 81st Medical Group, Keesler Air Force Base, 2532 Melville Ln., Biloxi, MS 39534, USA \\ ${ }^{\mathrm{b}}$ U.S. Army-Baylor University Doctoral Program in Physical Therapy (MCCS-HMT), Army Medical Department Center and School, 3151 Scott Rd, Rm 2307, \\ Fort Sam Houston, TX 78234, USA \\ ${ }^{c}$ Department of Biostatistics, University of Florida, PO Box 100177, Gainesville, FL 32610-0177, USA \\ ${ }^{\mathrm{d}}$ Telemedicine and Advanced Technology Research Center, U.S. Army Medical Research and Material Command, Ft Detrick, MD 21774, USA \\ ${ }^{\mathrm{e}}$ Center for Pain Research and Behavioral Health, University of Florida, PO Box 100165, Gainesville, FL 32610, USA \\ ${ }^{\mathrm{f}}$ Department of Clinical and Health Psychology, University of Florida, PO Box 100165, Gainesville, FL 32610, USA \\ ${ }^{\mathrm{g}}$ Department of Physical Therapy, University of Florida, PO Box 100154, Gainesville, FL 32610, USA \\ Received 1 February 2012; revised 18 February 2013; accepted 7 March 2013
}

\begin{abstract}
BACKGROUND CONTEXT: Effective strategies for preventing low back pain (LBP) have remained elusive, despite annual direct health care costs exceeding $\$ 85$ billion dollars annually. In our recently completed Prevention of Low Back Pain in the Military (POLM) trial, a brief psychosocial education program (PSEP) that reduced fear and threat of LBP reduced the incidence of health care-seeking for LBP.

PURPOSE: The purpose of this cost analysis was to determine if soldiers who received psychosocial education experienced lower health care costs compared with soldiers who did not receive psychosocial education.

STUDY DESIGN/SETTING: The POLM trial was a cluster randomized trial with four intervention arms and a 2-year follow-up. Consecutive subjects $(n=4,295)$ entering a 16-week training program at Fort Sam Houston, TX, to become a combat medic in the U.S. Army were considered for participation.

METHODS: In addition to an assigned exercise program, soldiers were cluster randomized to receive or not receive a brief psychosocial education program delivered in a group setting. The Military Health System Management Analysis and Reporting Tool was used to extract total and LBP-related health care costs associated with LBP incidence over a 2-year follow-up period.

RESULTS: After adjusting for postrandomization differences between the groups, the median total LBP-related health care costs for soldiers who received PSEP and incurred LBP-related costs during the 2-year follow-up period were \$26 per soldier lower than for those who did not receive PSEP ( $\$ 60$ vs. $\$ 86$, respectively, $\mathrm{p}=.034$ ). The adjusted median total health care costs for soldiers who received PSEP and incurred at least some health care costs during the 2-year follow-up period were estimated at $\$ 2$ per soldier lower than for those who did not receive PSEP ( $\$ 2,439$ vs. $\$ 2,441$,
\end{abstract}

FDA drug/device status: Not applicable.

Author disclosures: JDC: Grant: Department of Defense CDMRP (F, Paid directly to institution); Stock Ownership: Evidence in Motion (unknown shares, 20\% ownership), Texas Physical Therapy Specialists (unknown shares, 25\% ownership). SSW: Grant: Department of Defense (D, Paid directly to institution); Support for travel to meetings for the study or other purposes: Department of Defense (A, Paid directly to institution). DST: Grant: Department of Defense CDMRP (H, Paid directly to institution). MER: Grant: Department of Defense (unknown amount, Paid directly to institution). SZG: Grant: Department of Defense (E, Paid directly to institution); Support for travel to meetings for the study or other purposes: Department of Defense (B, Paid directly to institution); Scientific Advisory Board: American Physical Therapy Association (B); Other Office: American Physical Therapy Association (B).

The disclosure key can be found on the Table of Contents and at www. TheSpineJournalOnline.com.

Trial registration: NCT00373009 at ClinicalTrials.gov - http://clinicaltrials. gov/.

* Corresponding author. Department of Physical Therapy (MSGS/ SGCUY), 81st Medical Group, Keesler Air Force Base, 2532 Melville Ln., Biloxi, MS 39534, USA. Tel.: (210) 364-7410; fax: (210) 579-2637. E-mail address: childsjd@gmail.com (J.D. Childs) 
respectively, $\mathrm{p}=.242$ ). The results from this analysis demonstrate that a brief psychosocial education program was only marginally effective in reducing LBP-related health care costs and was not effective in reducing total health care costs. Had the 1,995 soldiers in the PSEP group not received PSEP, we would estimate that $16.7 \%$ of them would incur an adjusted median LBP-related health care cost of $\$ 517$ compared with the current $15.0 \%$ soldiers incurring an adjusted median cost of $\$ 399$, which translates into an actual LBP-related health care cost savings of $\$ 52,846$ during the POLM trial. However, it is likely that the unaccounted for direct and indirect costs might erase even these small cost savings.

CONCLUSION: The results of this study will help to inform policy- and decision-making regarding the feasibility of implementing psychosocial education in military training environments across the services. It would be interesting to explore in future research whether cost savings from psychosocial education could be enhanced given a more individualized delivery method tailored to an individual's specific psychosocial risk factors. Published by Elsevier Inc.

Keywords: $\quad$ Costs; Low back pain; Prevention; Biopsychosocial; Military

\section{Introduction}

Next to the common cold, low back pain (LBP) is the most common reason for visiting a physician in the United States and elsewhere [1] and represents a common form of chronic pain [2] and significant cause of disability in society $[3,4]$. Annual direct health care costs in the United States for spine disorders has been estimated at more than $\$ 85$ billion in 2005, corresponding to a $65 \%$ increase from 1997 estimates [4]. Moreover, indirect costs from lost work productivity resulting from LBP in the United States are estimated to exceed $\$ 7$ billion annually [5]. LBP is also one of the most common forms of chronic pain in the military and has been associated with high rates of medical evacuation for service members participating in Operation Iraqi Freedom or Operation Enduring Freedom in Afghanistan, with return to duty being uncertain [6-8]. It is not surprising then that primary prevention of LBP is a significant research priority for both the general [9] and military populations, where it has been suggested that implementation of preventive measures for service members at highest risk of evacuation could reduce the effect of non-battlerelated injuries and disease on military readiness [6]. However, effective strategies for preventing LBP have remained elusive, as highlighted by the European Guidelines for Prevention of Low Back Pain [10] and a recent systematic review on the topic [11].

In response, we recently completed the Prevention of Low Back Pain in the Military (POLM) trial, which was a cluster randomized study with four intervention arms and a 2-year follow-up [12-18]. Based on our primary outcome, there were no differences in low back incidence resulting in the seeking of health care between those receiving traditional versus core stabilization exercise. This negative finding for exercise was somewhat surprising because core stabilization has been advocated as preventive, yet offered no such benefit when compared with traditional military training in this trial [13]. In contrast, a brief psychosocial education program that reduced fear and threat of LBP [14] reduced the incidence of health care-seeking for LBP regardless of the assigned exercise approach, resulting in a decrease over 2 years (numbers needed to treat $=30.3,95 \%$ confidence interval $[\mathrm{CI}]=18.2-90.9)$ [13].

A few studies have found that early access to exercise and education approaches during the acute phase of LBP reduces subsequent health care costs [19-21]. However, no studies we are aware of have examined the implications of psychosocial education on subsequent health care costs in a primary prevention model. It would be interesting to understand the economic implications of receiving psychosocial education given the low cost and feasibility of delivering a brief psychosocial education program combined with the fact that this arm of the trial was shown to reduce health care-seeking for LBP. Furthermore, increasing the recognition of pain as a significant public health problem in the United States and exploring population-based methods of delivering pain education were key premises behind the Institute of Medicine's recent report on managing pain in America [22]. The results of this analysis will help to inform whether a military cohort receiving psychosocial education also incurred lower health care costs for LBP, and positive findings could provide important information for future investigations. Therefore, the purpose of this analysis was to determine if soldiers who received psychosocial education experienced lower health care costs compared with soldiers who did not receive psychosocial education. We hypothesized that, consistent with the incidence data, soldiers who received psychosocial education would have lower total and LBP-related costs during the 2-year follow-up period.

\section{Methods}

This study reports a planned secondary analysis in the Prevention of Low Back Pain in the Military clinical trial (NCT00373009), which has been registered at http:// clinicaltrials.gov [12,13]. Consecutive subjects entering 
a 16-week training program at Fort Sam Houston, TX, to become a combat medic in the U.S. Army were considered for participation. In the primary trial, 20 companies of Soldiers were cluster randomized to complete one of four training programs: a traditional exercise program including bent-knee sit-ups with $(n=945)$ or without $(n=1,212)$ a psychosocial education program (PSEP) or a core stabilization exercise program with $(n=1,049)$ or without PSEP $(\mathrm{n}=1,089)$ [13]. The Military Health System (MHS) Management Analysis and Reporting Tool (M2) was used to extract total and LBP-related health care costs associated with LBP incidence over a 2-year follow-up period. To analyze the health care costs for the purpose of this secondary analysis, we collapsed the four groups into two groups (PSEP vs. no PSEP) because there was no difference in health care-seeking for LBP based on the assigned exercise program found in the primary trial [13].

\section{Setting and participants}

Research staff at Fort Sam Houston, TX, introduced the study to individual companies of soldiers and obtained written informed consent. Refer to the Figure for a flow diagram describing the number of companies and soldiers considered for this trial, eventually enrolled into the trial, and the number of evaluable soldiers at the 2-year followup period, per the Consolidated Standards of Reporting Trials guidelines [23]. All subjects were recruited during a training orientation session attended by all soldiers as part of their in-processing for combat medic training. For 8 consecutive months, subjects were screened for eligibility according to the inclusion/exclusion criteria. Subjects were required to be 18 to 35 years of age (or a 17-year-old emancipated minor), participating in training to become a combat medic, and be able to speak and read English. Subjects with a prior history of LBP were excluded. A prior history of LBP was operationally defined as LBP that limited work or physical activity, lasted longer than 48 hours, and caused the subject to seek health care. Subjects were also excluded if they were currently seeking medical care for LBP; unable to participate in unit exercise because of an injury in the foot, ankle, knee, hip, neck, shoulder, elbow, wrist, or hand; had a history of fracture (stress or traumatic) in the proximal femur, hip, or pelvis; were pregnant; or if they had transferred from another training group. Other possible exclusions included soldiers who were being accelerated into a company already randomized and recruited for participation in the POLM trial or soldiers who were being reassigned to an occupational specialty other than a combat medic.

\section{Ethics approval}

The institutional review boards at the Brooke Army Medical Center (San Antonio, TX) and the University of Florida (Gainesville, FL) granted approval for this project.
All subjects provided written informed consent before their participation.

\section{Exercise programs}

Subjects performed the assigned exercise program in a group setting under the direct supervision of their drill instructors as part of daily unit physical training. The subjects' drill instructors received comprehensive training in the study procedures by the staff before the study's initiation. Drill instructors were provided detailed training cards specific to each program. This information was also provided to the drill instructors on the study's website (http://polm.ufl.edu) for reference purposes. This training ensured that both the drill instructors and subjects were proficient in their assigned exercise programs and enhanced the ability to accomplish the exercise programs in a standardized manner. Study personnel monitored physical training an average of 2 days per week over the 12-week training period to answer questions and monitor compliance with the assigned exercise program.

The exercise regimen in both groups consisted of five to six exercises, each of which was performed for one minute. Exercise programs were performed daily, for a total dosage time of approximately 5 minutes per day, 4 days per week over a period of 12 weeks. Performing the exercise programs under the supervision of a drill instructor and in a group setting helped to ensure compliance with the assigned program and dosage. Additional details regarding each exercise program can be found elsewhere [12,13,15], but are not included in this article because the focus of this secondary analysis is on health care costs associated with receiving psychosocial education.

\section{PSEP}

The dose and format of the PSEP was dependent on the time the investigative team had access to the soldiers outside of the training day, which was limited because of their busy training schedule. As a result, we elected to deliver the PSEP in a single group session during the first week of training that lasted no more than 1 hour. For the education program, the company was divided into two or three groups to accommodate the size of the lecture hall and also to allow for flexibility in scheduling soldiers. Each group received the same information, and the session involved an interactive lecture led by study personnel lasting approximately 45 minutes. The lecture consisted of a visual presentation followed by a question and answer session. The theoretical rationale for and content within the PSEP is described in more detail in a previous POLM publication [14].

\section{Randomization}

Military training environments require living in close quarters with other members of the unit, making individual randomization an unfeasible option for this trial because of 


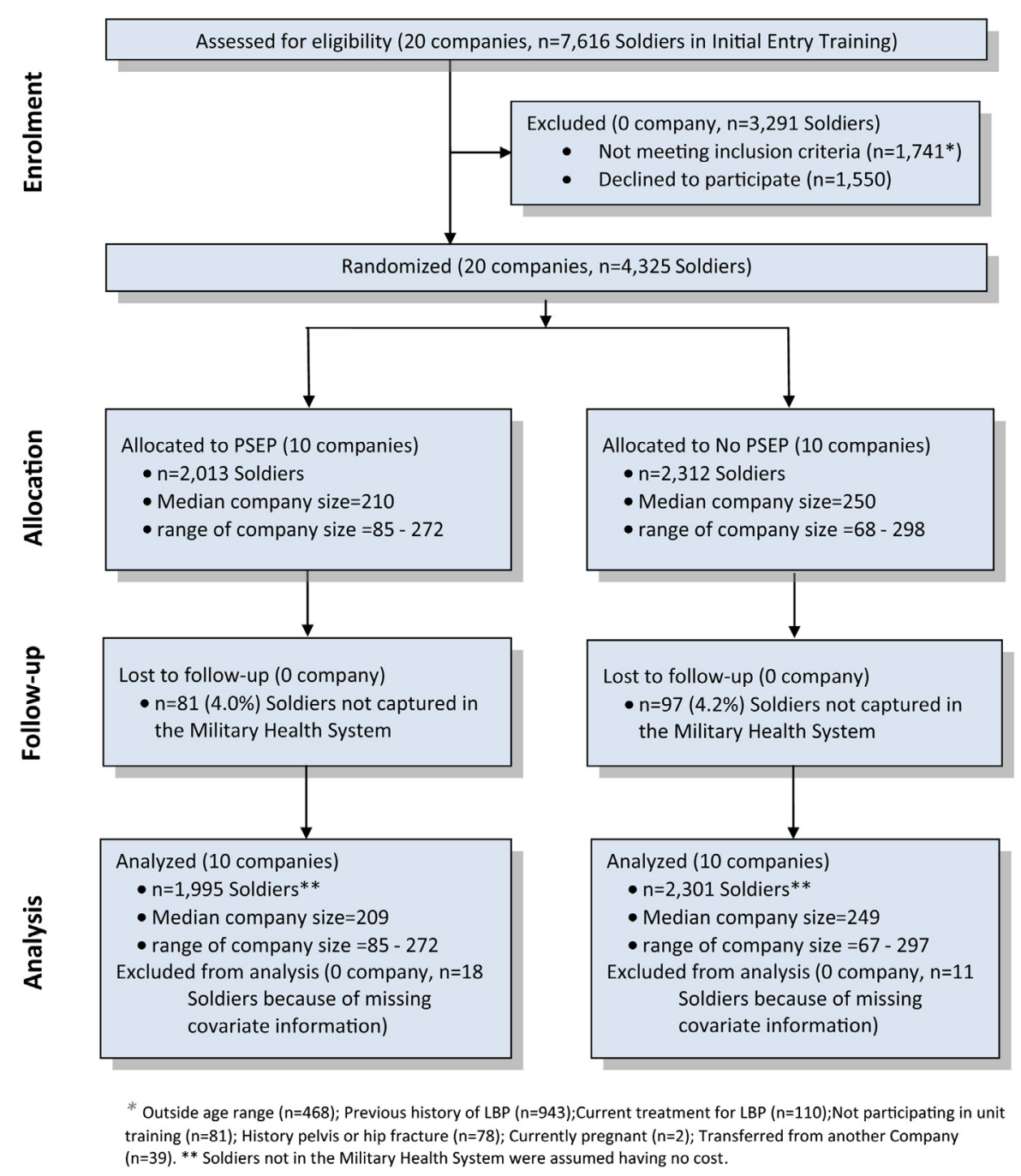

Figure. Flow diagram of clusters and individuals from recruitment to analysis.

concerns related to disruption of normal training schedule and treatment contamination. Therefore, a cluster randomization strategy was used for assigning companies to receive traditional exercise program or core stabilization exercise program. This meant that for a given company, every subject who consented to the study received the same study condition. Cluster randomization is a viable methodological choice that has been effectively used in other large samples of primary prevention $[24,25]$. The randomization schedule was prepared by computer and was determined before recruitment began. The randomization schedule was balanced to ensure equal allocation to each condition after 12 companies were recruited.

\section{Blinding}

It was not possible to mask soldiers because they actively participated in the exercise and education training programs. All outcomes for the primary analysis was assessed by raters blinded to group assignment or were obtained via self-report [13].

\section{Baseline measures}

Measures were collected under supervision of research personnel unaware of random company assignment and scored in a masked manner by computer algorithm. Soldiers completed standard demographic information, such as age, sex, medical history, and factors related to military status. Soldiers also completed self-report measures at baseline for physical and mental function [26], anxiety [27], depressive symptoms [28], fear of pain [29], and back beliefs [30].

\section{Sample size estimation and power analysis}

The sample size estimates were based on the primary outcome of LBP incidence, which intended to recruit a minimum of 16 companies based on the assumption of 150 consenting soldiers per company. A more detailed sample size estimation and power analysis was published with our trial protocol [12]. The study sample size $(\mathrm{N}=4,325)$ could enable us to have $80 \%$ power to detect a mean 
difference of 0.115 in log-cost (ie, $12 \%$ difference in cost) between PSEP and no-PSEP groups, assuming that the $\log$-cost has a within-group standard deviation of 1.35 as observed among the soldiers who incurred health care costs.

\section{Outcomes}

M2 is an ad hoc query tool that enhances support to health care managers to oversee MHS operations. The database is updated monthly via an electronic feed from each of the Military Treatment Facility regions worldwide and currently reflects the combined experience of more than 9 million MHS beneficiary members. Maintained by the Tricare Management Activity, M2 links claims data and demographic data to give a comprehensive view of population, clinical, and financial health utilization and cost data and is integrated with eligibility and enrollment data. M2 was used to extract associated health care costs associated with utilization of health care because of its comprehensive nature. For example, M2 includes data from both the direct care system (care provided in military treatment facilities) and commercial network claims (care provided to MHS beneficiaries at civilian facilities) worldwide. Additionally, the data collected to populate the M2 database include health care use while soldiers are deployed to areas such as Iraq or Afghanistan. Our interest in using a health care-seeking definition of experiencing LBP was driven by studies indicating continuing high rates of health care utilization for LBP [31,32], with trends of greatly increasing cost, but of no obvious benefit to the population $[4,33]$. In addition, the validity of self-report measures for determining LBP has been questioned for military populations [34], and use of a health care database mitigated these concerns.

\section{Extraction of health care cost data}

The M2 database was searched for relevant LBP-related International Classification of Diseases (ICD) codes for soldiers enrolled in the POLM trial. We used similar strategies to operationally define LBP as has been published in other studies, using ICD codes to identify subjects seeking health care for LBP $[19,35]$. Before being transferred to the investigators, all traceable person-specific identifying factors were transformed into anonymous, coded study numbers to protect subjects' privacy.

Patients were required to be continuously eligible within the database for 6 months before the index date (in addition to 24 months after the index date to define the 24-month episode of care) to identify comorbid conditions that may influence LBP prognosis, including mental health conditions (depression, anxiety, bipolar, or other psychotic disorders), neck or thoracic pain, and fibromyalgia using relevant ICD-9 codes (Table 1). Within this period, we recorded the number of unique ICD-9 diagnoses in any setting and
Table 1

ICD-9 codes that were used to identify comorbid conditions

\begin{tabular}{|c|c|}
\hline Code & Description \\
\hline \multicolumn{2}{|c|}{ Comorbid mental health conditions } \\
\hline 296.xx & Affective psychoses \\
\hline 297.xx & Delusional disorders \\
\hline 298.xx & Other nonorganic psychoses \\
\hline 300.xx & Neurotic disorders \\
\hline 301.xx & Personality disorders \\
\hline 308.xx & Acute reaction to stress \\
\hline 309.xx & Adjustment reaction \\
\hline 311.xx & Depressive disorders, not elsewhere classified \\
\hline \multicolumn{2}{|c|}{ Comorbid neck/thoracic pain conditions } \\
\hline 721.0 & Cervical spondylosis without myelopathy \\
\hline 721.1 & Cervical spondylosis with myelopathy \\
\hline 721.2 & Thoracic spondylosis without myelopathy \\
\hline 721.41 & Spondylogenic compression of thoracic spinal cord \\
\hline 722.0 & $\begin{array}{l}\text { Displacement of cervical intervertebral disc without } \\
\text { myelopathy }\end{array}$ \\
\hline 722.4 & Degeneration of cervical intervertebral disc \\
\hline 722.51 & Intervertebral disc disorder, thoracic, or thoracolumbar region \\
\hline 722.71 & Intervertebral disc disorder without myelopathy-cervical \\
\hline 722.72 & Intervertebral disc disorder without myelopathy, thoracic region \\
\hline 722.81 & Post-laminectomy syndrome-cervical \\
\hline 722.91 & other unspecified disc disorder-cervical region \\
\hline 723.xx & Other disorders of cervical region \\
\hline 724.1 & Pain in thoracic spine \\
\hline 739.1 & Non-allopathic lesions not otherwise specified-cervical region \\
\hline 805 & Fracture of cervical spine without spinal cord injury \\
\hline 847.0 & Sprains and strains of other, unspecified part of the back-neck \\
\hline 953.0 & Injury to nerve root and spinal plexus-cervical \\
\hline 954.0 & Injury to other nerves of trunk-cervical \\
\hline \multicolumn{2}{|c|}{ Comorbid fibromyalgia } \\
\hline 729.1 & Myalgia and myositis, unspecified \\
\hline
\end{tabular}

the number of prescription medications based on unique generic product identifiers. We recorded if a hospitalization occurred for any reason, if opioid medications were prescribed, and the total costs for all services during this period including inpatient, outpatient, and prescriptions.

Additional descriptive data were abstracted, as available, to permit risk-adjustment in the data analysis. We recorded the following covariates at the index date: patient's demographic information including age, race, sex, education level, and income; factors related to military status such as active duty status, time in Army; and self-report measures at baseline for physical and mental function, anxiety, depressive symptoms, fear of pain, and back beliefs.

\section{Statistical analysis}

All statistical analyses were performed using the SAS software, version 9 (SAS Institute Inc, Cary, NC, USA). Descriptive statistics, including mean, standard deviation, median, and range of all health care costs, were presented by intervention group and type of health care service. Also presented are mean and standard deviation of logtransformed costs. Both Wilcoxon rank sum test (which is based on rank scores of medical costs) and two-sample $t$-test (which is based on log-transformed test) were performed to compare the PSEP and no-PSEP groups across 
Table 2

Comparison of baseline characteristics between soldiers who received PSEP versus those who did not

\begin{tabular}{|c|c|c|c|c|c|}
\hline \multirow[b]{2}{*}{ Variable } & \multirow[b]{2}{*}{ Label } & \multirow{2}{*}{$\frac{\text { Overall }}{\mathrm{N}=4,325}$} & \multirow{2}{*}{$\frac{\text { PSEP }}{n=2,013}$} & \multirow{2}{*}{$\frac{\text { No PSEP }}{n=2,312}$} & \multirow[b]{2}{*}{$\mathrm{p}$ Value } \\
\hline & & & & & \\
\hline \multicolumn{6}{|l|}{ Innate Characteristics } \\
\hline Age $(\mathrm{N}=4,319)$ & & $22.0 \pm 4.2$ & $22.3 \pm 4.4$ & $21.7 \pm 4.0$ & $<.0001$ \\
\hline \multirow[t]{2}{*}{ Gender } & Male & 3,082 & $1,454(72.6 \%)$ & $1,628(70.6 \%)$ & .155 \\
\hline & Female & 1,226 & $549(27.4 \%)$ & $677(29.4 \%)$ & \\
\hline \multirow[t]{4}{*}{ Race } & Black or African & 420 & $202(10.1 \%)$ & $218(9.4 \%)$ & .354 \\
\hline & Hispanic & 426 & $183(9.1 \%)$ & $243(10.5 \%)$ & \\
\hline & White or Caucasian & 3,190 & $1,496(74.6 \%)$ & $1,694(73.3 \%)$ & \\
\hline & Other & 279 & $124(6.2 \%)$ & $155(6.7 \%)$ & \\
\hline \multirow[t]{3}{*}{ Education } & High school or lower & 1,935 & $851(42.3 \%)$ & $1,084(46.9 \%)$ & .0019 \\
\hline & Some college & 1,998 & $988(49.1 \%)$ & $1,010(43.7 \%)$ & \\
\hline & College or higher & 391 & $174(8.6 \%)$ & $217(9.4 \%)$ & \\
\hline \multirow[t]{2}{*}{ Income } & Less than $\$ 20,000$ & 2,125 & $922(45.9 \%)$ & $1,203(52.2 \%)$ & $<.0001$ \\
\hline & Greater than $\$ 20,000$ & 2,188 & $1,085(54.1 \%)$ & $1,103(47.8 \%)$ & \\
\hline \multirow[t]{3}{*}{ Active duty } & Active & 2,532 & $1,070(53.2 \%)$ & $1,462(63.3 \%)$ & $<.0001$ \\
\hline & Reserve & 1,782 & $935(46.5 \%)$ & $847(36.7 \%)$ & \\
\hline & Other & 8 & $7(0.3 \%)$ & $1(0.0 \%)$ & \\
\hline \multirow[t]{3}{*}{ Time in Army } & $<5$ months & 2,691 & $1,186(58.9 \%)$ & $1,505(65.2 \%)$ & $<.0001$ \\
\hline & 5 months -1 year & 969 & $471(23.4 \%)$ & $498(21.6 \%)$ & \\
\hline & $>1$ year & 661 & $355(17.6 \%)$ & $306(13.3 \%)$ & \\
\hline \multicolumn{2}{|l|}{ Height } & $68.3 \pm 3.9$ & $68.4 \pm 3.9$ & $68.3 \pm 3.8$ & .265 \\
\hline \multicolumn{2}{|l|}{ Weight } & $164.8 \pm 27.7$ & $165.4 \pm 28.0$ & $164.3 \pm 27.3$ & .188 \\
\hline \multicolumn{2}{|l|}{ BMI } & $24.8 \pm 3.1$ & $24.8 \pm 3.2$ & $24.7 \pm 3.1$ & .480 \\
\hline \multicolumn{6}{|l|}{ Psychological } \\
\hline \multicolumn{2}{|l|}{ BDI total } & $6.4 \pm 6.6$ & $6.3 \pm 6.4$ & $6.5 \pm 6.7$ & .404 \\
\hline \multicolumn{2}{|l|}{ FPQ total } & $18.1 \pm 5.9$ & $18.2 \pm 5.7$ & $17.9 \pm 6.0$ & .070 \\
\hline \multicolumn{2}{|l|}{ BBQ total } & $43.4 \pm 7.1$ & $43.1 \pm 7.1$ & $43.6 \pm 7.0$ & .018 \\
\hline \multicolumn{2}{|l|}{ STAI } & $36.0 \pm 9.1$ & $36.0 \pm 9.0$ & $36.0 \pm 9.2$ & .864 \\
\hline \multicolumn{6}{|c|}{ Baseline health status and physical activity } \\
\hline \multicolumn{2}{|c|}{ PCS total } & $53.4 \pm 5.2$ & $53.3 \pm 5.2$ & $53.5 \pm 5.2$ & .092 \\
\hline \multicolumn{2}{|l|}{ MCS total } & $49.2 \pm 8.6$ & $49.1 \pm 8.6$ & $49.2 \pm 8.6$ & .560 \\
\hline \multicolumn{2}{|l|}{ SF12 total } & $102.6 \pm 9.2$ & $102.3 \pm 9.2$ & $102.7 \pm 9.1$ & .134 \\
\hline \multirow[t]{2}{*}{ Smoke before entering Army } & Yes & 1,552 & $736(36.6 \%)$ & $816(35.3 \%)$ & .398 \\
\hline & No & 2,771 & $1,277(63.4 \%)$ & $1,494(64.7 \%)$ & \\
\hline \multirow[t]{2}{*}{ Exercise routinely } & Yes & 2,220 & $1,033(51.3 \%)$ & $1,187(51.4 \%)$ & .977 \\
\hline & No & 2,102 & $979(48.7 \%)$ & $1,123(48.6 \%)$ & \\
\hline
\end{tabular}

BBQ, Back Beliefs Questionnaire; BDI, Beck Depression Inventory; BMI, body mass index; FPQ, Fear of Pain Questionnaire; MCS, Mental Component Subscale; PCS, Physical Component Subscale; PSEP, psychosocial education program; SF12, Short Form 12; STAI, State Trait Anxiety Index.

all types of health care costs. Demographic and baseline levels of clinical variables were compared between the two intervention groups (PSEP vs. no-PSEP) using analysis of variance for means and chi-square tests for proportions (Table 2). Variables that differed between the groups were considered in the final analyses, in addition to prespecified covariates of gender and age.

Furthermore, we estimated the effect of the intervention group based on a two-part model, adjusting for the baseline variables listed in Table 2 and considering the withincluster correlation by including a random effect for company. The model consists of two parts: a logistic regression model for the probability of incurring health care costs (ie, having health care cost, yes/no); and conditioned on the event, a log-linear model for the amount of health care costs. Such a two-part model enables us to estimate the total health care costs for each combined levels of the intervention group and other covariates, using the product of probability of incurring a cost and amount of cost conditioned on the event.

\section{Role of the funding source}

This study was funded by the Department of Defense's Peer Reviewed Medical Research Program (\#W81XWH06-1-0564). The funding agency played no role in the design, conduct, or reporting of the study or in the decision to submit the manuscript for publication.

\section{Results}

Figure provides information on study enrollment, assignment to the PSEP or no PSEP group, and the availability of health care cost data in the M2 database. Table 2 provides baseline characteristics based on whether soldiers received PSEP or no PSEP. Baseline differences between the groups were found in age, education, income, active duty status, 
Table 3

Summary of LBP-related health care costs per soldier by PSEP group for soldiers who incurred LBP-related health care costs for at least one LBP episode during the 2-year follow-up period

\begin{tabular}{|c|c|c|c|c|}
\hline Variable & Overall & PSEP & No PSEP & $\mathrm{p}$ Value \\
\hline Number (\%) with LBP related cost & $\mathrm{n}=677(15.8 \%)$ & $\mathrm{n}=286(14.3 \%)$ & $\mathrm{n}=391(17.0 \%)$ & .017 \\
\hline \multicolumn{5}{|l|}{ Full cost } \\
\hline Median [minimum, maximum] & $431.6[10.1,19,029.8]$ & $378.1[11.4,10,816.7]$ & $484[10.1,19,029.8]$ & .035 \\
\hline \multicolumn{5}{|l|}{$\log ($ full cost $)$} \\
\hline Mean \pm SD & $6.21 \pm 1.18$ & $6.10 \pm 1.25$ & $6.29 \pm 1.11$ & .033 \\
\hline Median [minimum, maximum] & $32.9[0,1,069.9]$ & $30.9[0,861.1]$ & $35[0,1,069.9]$ & .246 \\
\hline \multicolumn{5}{|l|}{$\log$ (clinician salary) } \\
\hline Mean \pm SD & $3.54 \pm 1.31$ & $3.47 \pm 1.33$ & $3.59 \pm 1.31$ & .259 \\
\hline \multicolumn{5}{|l|}{ Lab cost } \\
\hline Mean \pm SD & $44.1 \pm 66.0$ & $38.7 \pm 52.4$ & $48.0 \pm 74.2$ & \\
\hline Median [minimum, maximum] & $24.5[0,898.9]$ & $19.5[0,419.3]$ & $27.1[0,898.9]$ & .003 \\
\hline Median [minimum, maximum] & $175.2[0,7,775.5]$ & $160.4[0,7,684.2]$ & $188.1[0,7,775.5]$ & .107 \\
\hline \multicolumn{5}{|l|}{$\log ($ other cost) } \\
\hline Mean \pm SD & $5.29 \pm 1.34$ & $5.19 \pm 1.44$ & $5.36 \pm 1.26$ & .096 \\
\hline \multicolumn{5}{|l|}{ Other ancillary } \\
\hline Mean \pm SD & $56.0 \pm 191.1$ & $46.1 \pm 94.2$ & $63.3 \pm 238.0$ & \\
\hline Median [minimum, maximum] & $19.5[0,4,362.7]$ & $19.2[0,873.8]$ & $22.1[0,4,362.7]$ & .054 \\
\hline \multicolumn{5}{|l|}{$\log$ (other ancillary) } \\
\hline Mean \pm SD & $2.85 \pm 1.61$ & $2.72 \pm 1.60$ & $2.95 \pm 1.62$ & .068 \\
\hline \multicolumn{5}{|l|}{ Other salary } \\
\hline Mean \pm SD & $185.9 \pm 279.8$ & $179.4 \pm 256.2$ & $190.7 \pm 296.1$ & \\
\hline Median [minimum, maximum] & $86.4[0,3,242.5]$ & $82.8[0,1,569.2]$ & $91.8[0,3,242.5]$ & .084 \\
\hline \multicolumn{5}{|l|}{$\log$ (other salary) } \\
\hline Mean \pm SD & $4.54 \pm 1.26$ & $4.43 \pm 1.37$ & $4.63 \pm 1.17$ & .043 \\
\hline \multicolumn{5}{|l|}{$\log ($ radiology) } \\
\hline Mean \pm SD & $3.52 \pm 1.26$ & $3.36 \pm 1.36$ & $3.64 \pm 1.17$ & .004 \\
\hline
\end{tabular}

LBP, low back pain; PSEP, psychosocial education program.

time in the Army, company drill instructor, back beliefs, and whether the subject received a ultrasound imaging examination (Table 2); therefore, adjusted estimates were presented in subsequent two-part statistical analyses.

Table 3 presents summary statistics for LBP-related health care costs per soldier by PSEP group for soldiers who incurred LBP-related health care costs for at least one LBP episode during the 2-year follow-up period. Table 4 presents summary statistics for total health care costs per soldier by PSEP group for soldiers who incurred at least some health care costs during the 2-year followup period. For both Tables 3 and 4, the mean (standard deviation) and median (range) for the costs are presented. However, we emphasize reporting of median health care costs rather than the mean because it is a better measure of central tendency when predicting the cost liability. Specifically, the median is influenced less than the mean by a few outliers among individuals who incur extraordinarily high costs. This is consistent with the reporting of health care cost data in the medical literature [36]. LBP-related and total health care costs are further categorized based on the type of health care service that was incurred (clinician salary, other salary, pharmacy, radiology, laboratory, other ancillary, and other). Also presented are the mean and standard deviation of log-transformed costs. Both the nonparametric Kruskal-Wallis test (which is based on rank scores of health care costs) and analysis of variance test (which is based on log-transformed test) are provided. 
Table 4

Summary of health care costs per soldier by PSEP group for soldiers who incurred at least some health care costs during the 2-year follow-up period

\begin{tabular}{|c|c|c|c|c|}
\hline Variable & Overall & PSEP & No PSEP & $\mathrm{p}$ value \\
\hline Number $(\%)$ with Cost & $\mathrm{n}=3,913(91.1 \%)$ & $\mathrm{n}=1,821(91.3 \%)$ & $\mathrm{n}=2,092(90.9 \%)$ & 679 \\
\hline \multicolumn{5}{|l|}{ Full cost } \\
\hline Mean \pm SD & $4,621.0 \pm 6,806.8$ & $4,322.9 \pm 6,322.4$ & $4,880.6 \pm 7,193.4$ & \\
\hline Median [minimum, maximum] & $2,363.1[8.1,109,842.4]$ & $2,199.2[8.3,83,874.5]$ & $2,556.4[8.1,10,9842.4]$ & .0001 \\
\hline \multicolumn{5}{|l|}{$\log ($ full cost $)$} \\
\hline Mean \pm SD & $7.70 \pm 1.32$ & $7.62 \pm 1.33$ & $7.77 \pm 1.30$ & .0002 \\
\hline \multicolumn{5}{|l|}{ Clinician salary } \\
\hline Mean \pm SD & $378.5 \pm 574.2$ & $360.2 \pm 553.6$ & $394.3 \pm 591.2$ & \\
\hline Median [minimum, maximum] & $189.4[0,8,316.4]$ & $176.3[0,8,085.2]$ & $201.4[0,8,316.4]$ & .011 \\
\hline \multicolumn{5}{|l|}{$\log$ (clinician salary) } \\
\hline Mean \pm SD & $5.17 \pm 1.35$ & $5.11 \pm 1.37$ & $5.22 \pm 1.34$ & .008 \\
\hline \multicolumn{5}{|l|}{ Lab cost } \\
\hline Mean \pm SD & $223.5 \pm 326.5$ & $204.5 \pm 293.0$ & $240.1 \pm 352.3$ & \\
\hline Median [minimum, maximum] & $113.5[0,4,626.3]$ & $103.5[0,3,119]$ & $121.6[0,4,626.3]$ & $<.0001$ \\
\hline \multicolumn{5}{|l|}{$\log (\operatorname{lab} \cos t)$} \\
\hline Mean \pm SD & $4.64 \pm 1.37$ & $4.55 \pm 1.37$ & $4.71 \pm 1.37$ & .000 \\
\hline \multicolumn{5}{|l|}{ Other cost } \\
\hline Mean \pm SD & $1,984.5 \pm 3,223.7$ & $1,871.3 \pm 3,154.0$ & $2,083.0 \pm 3,280.7$ & \\
\hline Median [minimum, maximum] & $988.4[0,63,794.3]$ & $931[2.2,52,237.1]$ & $1,076.5[0,63,794.3]$ & .0001 \\
\hline \multicolumn{5}{|l|}{$\log ($ other cost) } \\
\hline Mean $\pm S D$ & $6.83 \pm 1.33$ & $6.74 \pm 1.35$ & $6.91 \pm 1.30$ & .0001 \\
\hline \multicolumn{5}{|l|}{ Other ancillary } \\
\hline Mean $\pm S D$ & $350.2 \pm 749.5$ & $324.7 \pm 681.2$ & $372.3 \pm 803.7$ & \\
\hline Median [minimum, maximum] & $112.6[0,15,561.6]$ & $100.1[0,10,053.9]$ & $123.5[0,15,561.6]$ & .006 \\
\hline \multicolumn{5}{|l|}{$\log$ (other ancillary) } \\
\hline Mean \pm SD & $4.66 \pm 1.67$ & $4.61 \pm 1.63$ & $4.72 \pm 1.71$ & .040 \\
\hline \multicolumn{5}{|l|}{ Other salary } \\
\hline Mean \pm SD & $986.9 \pm 1,418.0$ & $911.4 \pm 1,281.1$ & $1,052.6 \pm 1,524.4$ & \\
\hline Median [minimum, maximum] & $524.6[0,21,734.5]$ & $483.6[2.2,13,185.8]$ & $565.4[0,21,734.5]$ & $<.0001$ \\
\hline \multicolumn{5}{|l|}{$\log$ (other salary) } \\
\hline Mean \pm SD & $6.14 \pm 1.37$ & $6.04 \pm 1.37$ & $6.22 \pm 1.35$ & .0001 \\
\hline \multicolumn{5}{|l|}{ Pharmacy } \\
\hline Mean \pm SD & $453.2 \pm 767.1$ & $422.6 \pm 679.7$ & $479.9 \pm 835.1$ & \\
\hline Median [minimum, maximum] & $195.5[0,11,237.7]$ & $177.9[0,7,570.5]$ & $215.8[0,11,237.7]$ & .002 \\
\hline \multicolumn{5}{|l|}{$\log$ (pharmacy) } \\
\hline Mean \pm SD & $5.14 \pm 1.57$ & $5.07 \pm 1.56$ & $5.21 \pm 1.58$ & .008 \\
\hline \multicolumn{5}{|l|}{ Radiology } \\
\hline Mean \pm SD & $244.3 \pm 347.0$ & $228.1 \pm 312.7$ & $258.4 \pm 373.8$ & \\
\hline Median [minimum, maximum] & $126.6[0,5,027.6]$ & $115.9[0,2,961.3]$ & $136.2[0,5,027.6]$ & .001 \\
\hline \multicolumn{5}{|l|}{$\log ($ radiology) } \\
\hline Mean \pm SD & $4.75 \pm 1.36$ & $4.67 \pm 1.37$ & $4.81 \pm 1.35$ & .001 \\
\hline
\end{tabular}

PSEP, psychosocial education program.

\section{Summary statistics for health care costs related to LBP}

There were $677(15.8 \%)$ soldiers who incurred health care costs for at least one LBP episode during the 2-year follow-up period. As expected and consistent with the primary findings, fewer soldiers who received PSEP incurred LBP-related health care costs $(n=286,14.3 \%)$ compared with those who did not receive PSEP $(n=391,17.0 \%)$ $(\mathrm{p}=.017)$ (Table 3). The median LBP-related health care costs per soldier who incurred costs attributable to at least one episode of LBP during the 2-year follow-up period was $\$ 432$ (range $=\$ 10-\$ 19,030$ ). Soldiers who received PSEP had significantly lower median LBP-related health care costs over the 2-year follow-up period (\$378 [range $=\$ 11-\$ 10,817])$ compared with those who did not receive PSEP $(\$ 484[$ range $=\$ 10-\$ 19,030])(p=.035$ with Wilcoxon rank sum test) (Table 3 ).

\section{Summary statistics for total health care costs}

Over the 2-year follow-up, the number of soldiers captured in the M2 database was 4,147/4,325 (95.9\%). Among the 4,296 soldiers included in the data analysis (after excluding 29 with missing covariate information), $3,913(91.1 \%)$ incurred at least some health care costs during the 2-year follow-up period. No differences existed in the number of soldiers who incurred at least some health care costs based on whether the soldier received PSEP $(\mathrm{n}=1,821,91.3 \%)$ or not $(\mathrm{n}=2,092,90.9 \%)(\mathrm{p}=.679)$ (Table 4). The median total health care costs per soldier 
Table 5

Effect of covariates on LBP-related costs estimated based on a two-part model (PSEP)

\begin{tabular}{|c|c|c|c|c|c|}
\hline Variable & Label & $\begin{array}{l}\text { Predicted probability } \\
\text { of having LBP related } \\
\text { medical cost }\end{array}$ & $\begin{array}{l}\text { Predicted LBP related } \\
\text { conditional cost }(\$)\end{array}$ & $\begin{array}{l}\text { Predicted cost by } \\
\text { two-part model }(\$)\end{array}$ & $\begin{array}{l}\text { Predicted cost } \\
\text { difference from } \\
\text { reference }(\$)\end{array}$ \\
\hline \multirow[t]{2}{*}{ PSEP } & No & 0.1665 & 516.99 & 86.07 & 26 \\
\hline & Yes & 0.1498 & 399.04 & 59.78 & 0 \\
\hline \multirow[t]{2}{*}{ Gender } & Male & 0.1665 & 516.99 & 86.07 & -69 \\
\hline & Female & 0.3315 & 466.49 & 154.63 & 0 \\
\hline \multirow[t]{4}{*}{ Race } & Black or Africa & 0.1917 & 723.62 & 138.74 & 26 \\
\hline & Hispanic & 0.1929 & 591.84 & 114.15 & 2 \\
\hline & White or Caucasian & 0.1665 & 516.99 & 86.07 & -26 \\
\hline & Other & 0.18 & 624.77 & 112.46 & 0 \\
\hline \multirow[t]{3}{*}{ Education } & High school or lower & 0.1578 & 463.51 & 73.15 & 5 \\
\hline & Some college & 0.1665 & 516.99 & 86.07 & 17 \\
\hline & College or higher & 0.1291 & 530.97 & 68.57 & 0 \\
\hline \multirow[t]{2}{*}{ Income } & Less than $\$ 20,000$ & 0.1336 & 471.93 & 63.07 & -23 \\
\hline & Greater than $\$ 20,000$ & 0.1665 & 516.99 & 86.07 & 0 \\
\hline \multirow[t]{2}{*}{ Active duty Status } & Active & 0.1665 & 516.99 & 86.07 & 42 \\
\hline & Reserve & 0.0799 & 548.16 & 43.82 & 0 \\
\hline \multirow[t]{2}{*}{ Smoke before entering Army } & Yes & 0.2025 & 555.1 & 112.4 & 26 \\
\hline & No & 0.1665 & 516.99 & 86.07 & 0 \\
\hline \multirow[t]{3}{*}{ Time in Army } & $<5$ months & 0.1665 & 516.99 & 86.07 & 14 \\
\hline & 5 months-1 year & 0.1372 & 447.57 & 61.39 & -11 \\
\hline & $<1$ year & 0.1384 & 520.55 & 72.03 & 0 \\
\hline \multirow[t]{2}{*}{ Exercise routinely } & Yes & 0.1665 & 516.99 & 86.07 & 11 \\
\hline & No & 0.1589 & 470.78 & 74.81 & 0 \\
\hline \multirow[t]{5}{*}{ Last APFT score } & $<150$ & 0.1791 & 336.01 & 60.17 & -85 \\
\hline & $150-200$ & 0.1844 & 627.11 & 115.65 & -30 \\
\hline & $200-250$ & 0.1665 & 516.99 & 86.07 & -59 \\
\hline & $250-300$ & 0.159 & 611.74 & 97.29 & -48 \\
\hline & $>300$ & 0.1674 & 867.57 & 145.23 & 0 \\
\hline \multirow[t]{2}{*}{ Profiled $^{\dagger}$} & Yes & 0.2012 & 582.86 & 117.29 & 31 \\
\hline & No & 0.1665 & 516.99 & 86.07 & 0 \\
\hline \multirow[t]{2}{*}{ Physical/USI exam } & No & 0.1665 & 516.99 & 86.07 & -16 \\
\hline & Yes & 0.1792 & 571.16 & 102.33 & 0 \\
\hline
\end{tabular}

APFT, Army Physical Fitness Test; LBP, low back pain; PSEP, psychosocial education program; USI, ultrasound imaging.

who incurred at least some health care costs during the 2year follow-up period was $\$ 2,363$ (range $=\$ 8-\$ 109,842$ ). Soldiers who received PSEP had significantly lower median total health care costs over the 2-year follow-up period $(\$ 2,199$ [range $=\$ 8-\$ 83,875])$ compared with those who did not receive PSEP $(\$ 2,556 \quad$ [range $=\$ 8-$ $\$ 109,842]) \quad(\mathrm{p}=.0001$ with Wilcoxon rank sum test $)$ (Table 4).

\section{Statistical analysis results based on two-part model}

Tables 5 and 6 present the estimated probability of having any LBP-related and total health care costs, respectively. In addition, they show the predicted conditional cost as well as the product of the two parts, which estimates the expected costs, including all visits. Table 5 presents the results when the costs were restricted to LBP-related visits. Soldiers who received PSEP had LBP-related costs that were \$26 lower per soldier compared with those who did not receive PSEP ( $\$ 60$ vs. $\$ 86$, respectively, $\mathrm{p}=.034$ ) (Table 5). After adjusting for other factors, soldiers who received PSEP had total health care costs that were only \$2 lower per soldier compared with those who did not receive PSEP ( $\$ 2,439$ vs. $\$ 2,441$, respectively, $p=.242$ ) (Table 6).

\section{Discussion}

Common chronic pain conditions affect at least 116 million U.S. adults at a cost of $\$ 560$ to $\$ 635$ billion annually in direct medical treatment costs and lost productivity [22]. A recent report from the Institute of Medicine was published to increase the recognition of pain as a significant public health problem in the United States and provide a roadmap for transforming the way pain is understood, assessed, treated, and prevented [22]. However, despite increasing medical expenditures dedicated toward its management, the prevalence of chronic, disabling LBP in particular continues to increase [4,31] and is among the most frequent causes of medical visits and lost-duty time in the MHS [37]. Moreover, LBP is the primary complaint of $53 \%$ of soldiers in Operation Iraqi Freedom/Operation Enduring Freedom who presented to military pain management center [8] and is a leading cause of medical evacuations from Iraq and Afghanistan [6], with only $2 \%$ returning to combat 
Table 6

Effect of covariates on total health care costs estimated based on a two-part model (PSEP)

\begin{tabular}{|c|c|c|c|c|c|}
\hline Variable & Label & $\begin{array}{l}\text { Predicted probability } \\
\text { of having LBP related } \\
\text { medical cost }\end{array}$ & $\begin{array}{l}\text { Predicted LBP related } \\
\text { conditional cost }(\$)\end{array}$ & $\begin{array}{l}\text { Predicted cost by } \\
\text { two-part model }(\$)\end{array}$ & $\begin{array}{l}\text { Predicted cost difference } \\
\text { from reference }(\$)\end{array}$ \\
\hline PSEP & No & 0.9556 & $2,554.29$ & $2,440.98$ & 2 \\
\hline \multirow[t]{2}{*}{ Gender } & Male & 0.9556 & $2,554.29$ & $2,440.98$ & $-2,451$ \\
\hline & Female & 0.9763 & $5,010.43$ & $4,891.91$ & 0 \\
\hline \multirow[t]{2}{*}{ Race } & Black or African & 0.9534 & $2,852.49$ & $2,719.46$ & 141 \\
\hline & Other & 0.9618 & $2,680.5$ & $2,578.14$ & 0 \\
\hline \multirow[t]{3}{*}{ Education } & High school or lower & 0.9507 & $2,591.26$ & $2,463.53$ & 275 \\
\hline & Some college & 0.9556 & $2,554.29$ & $2,440.98$ & 252 \\
\hline & College or higher & 0.9387 & $2,331.87$ & $2,188.99$ & 0 \\
\hline \multirow[t]{2}{*}{ Income } & $<\$ 20,000$ & 0.9553 & $2,508.65$ & $2,396.41$ & -45 \\
\hline & $>\$ 20,000$ & 0.9556 & $2,554.29$ & $2,440.98$ & 0 \\
\hline \multirow[t]{3}{*}{ Time in Army } & $<5$ months & 0.9556 & $2,554.29$ & $2,440.98$ & -27 \\
\hline & 5 months- 1 year & 0.9536 & $2,312.58$ & $2,205.19$ & -263 \\
\hline & $>1$ year & 0.9297 & $2,654.76$ & $2,468.16$ & 0 \\
\hline \multirow[t]{2}{*}{ Exercise routinely } & Yes & 0.9556 & $2,554.29$ & $2,440.98$ & -99 \\
\hline & No & 0.9541 & $2,662.23$ & $2,539.96$ & 0 \\
\hline \multirow[t]{5}{*}{ Last APFT score } & $<150$ & 0.8948 & $2,746.89$ & $2,457.93$ & 86 \\
\hline & $150-200$ & 0.957 & $3,042.64$ & $2,911.7$ & 540 \\
\hline & $200-250$ & 0.9556 & $2,554.29$ & $2,440.98$ & 69 \\
\hline & $250-300$ & 0.9582 & $2,402.67$ & $2,302.13$ & -69 \\
\hline & $>300$ & 0.9735 & $2,436.07$ & $2,371.55$ & 0 \\
\hline \multirow[t]{2}{*}{ Profiled } & Yes & 0.9646 & $3,432.33$ & $3,310.98$ & 870 \\
\hline & No & 0.9556 & $2,554.29$ & $2,440.98$ & 0 \\
\hline
\end{tabular}

APFT, Army Physical Fitness Test; LBP, low back pain; PSEP, psychosocial education program; USI, ultrasound imaging.

duty [8]. A recent study among veterans treated in a Veterans Administration regional health care network also found that LBP was significantly associated with increased risk of high-dose opioid use [38]. Moreover, in fiscal year 2010 (October 1, 2009, through September 30, 2010), approximately 70,000 individuals were recruited into the U.S. Army [39]. Therefore, it is understandable why identifying effective primary prevention strategies and their implications on subsequent health care costs is an important research priority.

In the primary analysis of the POLM trial, brief psychosocial education prevented LBP episodes regardless of the assigned exercise approach, resulting in a $3.3 \%(95 \% \mathrm{CI}$ : $1.1-5.5 \%$ ) decrease over 2 years (numbers needed to treat $=30.3,95 \% \quad C I=18.2-90.9) \quad$ [13]. Given the frequency of experiencing LBP and the high costs associated with its management, exploring the magnitude of cost savings with PSEP was an important further consideration. Table 2 illustrates that the two groups were significantly different in several characteristics at baseline. For example, the PSEP group had 2\% more male soldiers and $10 \%$ fewer soldiers on active duty, two factors that had a meaningful impact on health care costs, both favoring the PSEP group in the direction of lower health care costs. Therefore, it is important to interpret the results based on the more conservative adjusted estimates derived in the subsequent two-part statistical analyses presented in Tables 5 and 6. Total adjusted median health care costs for Soldiers who received PSEP and incurred at least some health care costs during the 2-year follow-up period were estimated at only $\$ 2$ per soldier lower than for those who did not receive PSEP $(\$ 2,439$ vs. $\$ 2,441$, respectively, $\mathrm{p}=.242$ ) (Table 5). We expect that the relative effect of PSEP on reducing LBP-related costs should be greater than the effect on total health care costs, which makes intuitive sense because PSEP is hypothesized to have a more pronounced and specific effect on LBP-related costs based on the underlying intent of psychosocial education, which in the POLM trial was to reduce the fear and threat of LBP [14]. Although there was indeed more relative effect of PSEP on reducing LBP-related costs, it was only marginally greater than the effect on total health care costs. Total adjusted median LBP-related health care costs for soldiers who received PSEP and incurred LBP-related costs during the 2-year follow-up period were $\$ 26$ per soldier lower than for those who did not receive PSEP ( $\$ 60$ vs. $\$ 86$, 
respectively, $\mathrm{p}=.034$ ) (Table 6). However, when put into context of actual cost savings in the POLM trial, the results are somewhat unremarkable. For example, had the 1,995 soldiers in the PSEP group not received PSEP, we would estimate that $16.7 \%$ of them would incur an adjusted median LBP-related health care cost of $\$ 517$ compared with the current $15.0 \%$ Soldiers incurring an adjusted median cost of $\$ 399$, which translates into an actual LBP-related health care cost savings of $\$ 52,846$ during the POLM trial.

Understanding the implications of psychosocial education on the implications of costs associated with specific types of health care services may assist policy-makers in the design of better care processes for patients with LBP. For example, overuse of expensive and often invasive examination procedures and treatments such as drugs and imaging have been shown to be of limited benefit for patients with LBP [33]. In this case, it is important to consider the direct and indirect costs of administering PSEP in the POLM trial. For example, there was negligible lost productivity because the PSEP was delivered within the existing training schedule. Although modest, the direct cost of materials used in the PSEP (ie, Back Book) costs approximately \$1 USD per soldier. Furthermore, given the minimal difference in cost between groups, even a modest estimate of total direct and indirect costs of administering PSEP (eg, instructor and other indirect costs such as space, utilities) may exceed any LBP-related cost savings that could be realized with PSEP. Therefore, more research should be conducted to determine if PSEP should be implement on a widespread scale, despite our findings from the primary trial results indicating a 3.3\% reduction in LBP incidence over 2 years [13].

The results of this analysis in a primary prevention model are more conservative than the results from other studies that have explored the cost-effectiveness of a psychosocial-focused approach in a primary care treatment model for patients already having LBP [40]. Therefore, it may be that secondary prevention strategies currently offer more potential to reduce the epidemic of LBP than primary prevention strategies direct to the broader population, many of whom may develop clinically relevant LBP and/or recover without needing to access the health care system. Another important consideration when interpreting the results of this analysis is that the PSEP was brief because of the soldiers' busy training syllabus; thus, we had limited access to their time outside of training hours. Therefore, to maintain the feasibility of implementing psychosocial education throughout military training environments, we elected to deliver the psychosocial education program in a group setting during a single 1-hour session. One of the potential criticisms of this approach is that the psychosocial education program may have been underdosed. However, despite the pragmatic nature of the trial, the positive effect of the psychosocial education program on reducing health careseeking for LBP was encouraging [13]. Future research might consider whether an enhanced dose of PSEP achieves an increased reduction in LBP incidence and potentially a greater cost savings than what was realized in the POLM trial.

One of the strengths of this analysis is that we had a large randomized sample, thus we were able to achieve a high degree of precision in the reporting of the results. Many costeffectiveness studies with similarly large sample sizes are not randomized or might be randomized but have a small sample. However, given the baseline differences between the groups on several meaningful confounding factors, it is possible that differences on factors that were not collected may also exist. This could contribute to additional confounding that may further attenuate any cost benefit. Another limitation is that we did not calculate cost-effectiveness using commonly reported statistics (ie, quality-adjusted life years) because we were unable to directly assess the cost of delivering the psychosocial education program because it was delivered by the research team. The POLM trial was limited to Army soldiers completing training for a specific occupational specialty (combat medic). It is unknown whether similar findings would be observed in other military services, different occupational specialties, or outside of the training environment.

\section{Conclusion}

A brief PSEP achieved only modest savings that were specific to LBP-related health care costs. Furthermore, it is likely that unaccounted for direct and indirect costs might erase even these small cost savings. Therefore, more research is needed to determine if PSEP should be implemented on a widespread scale. The results of this study have important implications on policy- and decisionmaking regarding the feasibility of implementing psychosocial education in military training environments. It would be interesting to explore in future research whether cost savings from psychosocial education could be enhanced given a more individualized delivery method tailored to an individual's specific psychosocial risk factors.

\section{Acknowledgments}

The views expressed in this material are those of the authors, and do not reflect the official policy or position of the U.S. Government, Department of Defense, U.S. Army, or U.S. Air Force.

The POLM cluster randomized trial was supported by the Peer Reviewed Medical Research Program of the Department of Defense (PR054098). All authors were independent from this funding program and the funding program played no role in the design and conduct of the study; collection, management, analysis, and interpretation of the data; and preparation, review, or approval of the 
manuscript. All contributing authors had access to all study data and take final responsibility for paper submission.

The authors thank the leadership, cadre, and students from the 232nd Medical Battalion and the 32nd Medical Brigade for their support and study participation. Thanks to Major Scott Gregg and David H. Montplaisir, Jr., for compiling the health care cost data; Christopher Barnes, Yang Li, and Erik Henrickson for creation and management of the website and database; and Jessica Neff for assistance with data entry and confirmation. We also thank Yunfeng Dai for assistance with statistical analyses, Donna Cunningham for her administrative assistance, and various physical therapy students from the U.S. Army-Baylor University, University of Texas Health Science Center at San Antonio, Texas State University, University of Puget Sound, East Tennessee State University, and University of Colorado at Denver and Health Science Center.

Competing interests: The authors have no competing interests to declare with submission of this manuscript. All authors have completed the Unified Competing Interest form at www.icmje.org/coi_disclosure.pdf and these forms are available on request from the corresponding author. All authors received financial support from the Department of Defense to complete the submitted work; have no financial relationships with any organizations that might have an interest in the submitted work in the previous 3 years; and have no other relationships or activities that could appear to have influenced the submitted work.

Authors' contributions: J.D.C., S.S.W., D.S.T., M.E.R., and S.Z.G. were responsible for the initial conception of the research question, securing funding, supervising the protocol, and final manuscript preparation. S.S.W. was primarily responsible for data analysis, interpretation and reporting, whereas J.D.C., D.S.T., M.E.R., and S.Z.G. assisted with interpretation and reporting. All authors read, edited, and approved the final version of the manuscript.

\section{References}

[1] Patel AT, Ogle AA. Diagnosis and management of acute low back pain. Am Fam Physician 2000;61:1779-90.

[2] Mäntyselkä P, Kumpusalo E, Ahonen R, et al. Pain as a reason to visit the doctor: a study in Finnish primary health care. Pain 2001;89:175-80.

[3] Stewart WF, Ricci JA, Chee E, et al. Lost productive time and cost due to common pain conditions in the US workforce. JAMA 2003;290:2443-54.

[4] Martin BI, Deyo RA, Mirza SK, et al. Expenditures and health status among adults with back and neck problems. JAMA 2008;299: 656-64.

[5] Ricci JA, Stewart WF, Chee E, et al. Back pain exacerbations and lost productive time costs in United States workers. Spine 2006;31: 3052-60.

[6] Cohen SP, Brown C, Kurihara C, et al. Diagnoses and factors associated with medical evacuation and return to duty for service members participating in Operation Iraqi Freedom or Operation Enduring Freedom: a prospective cohort study. Lancet 2010;375:301-9.

[7] Cohen SP, Nguyen C, Kapoor SG, et al. Back pain during war: an analysis of factors affecting outcome. Arch Intern Med 2009;169: 1916-23.
[8] Cohen SP, Griffith S, Larkin TM, et al. Presentation, diagnoses, mechanisms of injury, and treatment of soldiers injured in Operation Iraqi Freedom: an epidemiological study conducted at two military pain management centers. Anesth Analg 2005;101:1098-103.

[9] Linton SJ, van Tulder MW. Preventive interventions for back and neck pain problems: what is the evidence? Spine 2001;26:778-87.

[10] Burton AK, Balagué F, Cardon G, et al. Chapter 2. European guidelines for prevention in low back pain: November 2004. Eur Spine J 2006;15(Suppl 2):S136-68.

[11] Bigos SJ, Holland J, Holland C, et al. High-quality controlled trials on preventing episodes of back problems: systematic literature review in working-age adults. Spine J 2009;9:147-68.

[12] George SZ, Childs JD, Teyhen DS, et al. Rationale, design, and protocol for the prevention of low back pain in the military (POLM) trial (NCT00373009). BMC Musculoskelet Disord 2007;8:92.

[13] George SZ, Childs JD, Teyhen DS, et al. Brief psychosocial education, not core stabilization, reduced incidence of low back pain: results from the Prevention of Low Back Pain in the Military (POLM) cluster randomized trial. BMC Med 2011;9:128.

[14] George SZ, Teyhen DS, Wu SS, et al. Psychosocial education improves low back pain beliefs: results from a cluster randomized clinical trial (NCT00373009) in a primary prevention setting. Eur Spine J 2009;18:1050-8.

[15] Childs JD, Teyhen DS, Benedict TM, et al. Effects of sit-up training versus core stabilization exercises on sit-up performance. Med Sci Sports Exerc 2009;41:2072-83.

[16] Childs JD, Teyhen DS, Casey PR, et al. Effects of traditional sit-up training versus core stabilization exercises on short-term musculoskeletal injuries in US Army soldiers: a cluster randomized trial. Phys Ther 2010;90:1404-12.

[17] Childs JD, Teyhen DS, Van Wyngaarden JJ, et al. Predictors of webbased follow-up response in the prevention of low back pain in the military trial (POLM). BMC Musculoskelet Disord 2011;12:132.

[18] Robinson ME, Teyhen DS, Wu SS, et al. Mental health symptoms in combat medic training: a longitudinal examination. Mil Med 2009; 174:572-7.

[19] Gellhorn AC, Chan L, Martin B, Friedly J. Management patterns in acute low back pain: the role of physical therapy. Spine 2010. Available at: http://www.ncbi.nlm.nih.gov/pubmed/21099735. Accessed May 29, 2011.

[20] Pinnington MA, Miller J, Stanley I. An evaluation of prompt access to physiotherapy in the management of low back pain in primary care. Fam Pract 2004;21:372-80.

[21] Pendergast J, Kliethermes SA, Freburger JK, Duffy PA. A comparison of health care use for physician-referred and self-referred episodes of outpatient physical therapy. Health Serv Res 2011. Available at: http://www.ncbi.nlm.nih.gov/pubmed/22092033. Accessed January 15, 2012.

[22] Committee on Advancing Pain Research, Care, and education; Institute of Medicine. Relieving pain in America: a blueprint for transforming prevention. Care Educ Res 2011. Available at: http://www. iom.edu/Reports/2011/Relieving-Pain-in-America-A-Blueprint-forTransforming-Prevention-Care-Education-Research.aspx. Accessed October 5, 2012.

[23] Campbell MK, Elbourne DR, Altman DG. CONSORT statement: extension to cluster randomised trials. BMJ 2004;328:702-8.

[24] Ornstein S, Jenkins RG, Nietert PJ, et al. A multimethod quality improvement intervention to improve preventive cardiovascular care: a cluster randomized trial. Ann Intern Med 2004;141:523-32.

[25] Olsen O-E, Myklebust G, Engebretsen L, et al. Exercises to prevent lower limb injuries in youth sports: cluster randomised controlled trial. BMJ 2005;330:449.

[26] Ware J Jr, Kosinski M, Keller SD. A 12-Item Short-Form Health Survey: construction of scales and preliminary tests of reliability and validity. Med Care 1996;34:220-33.

[27] Ramanaiah NV, Franzen M, Schill T. A psychometric study of the State-Trait Anxiety Inventory. J Pers Assess 1983;47:531-5. 
[28] Whisman MA, Perez JE, Ramel W. Factor structure of the Beck Depression Inventory-Second Edition (BDI-II) in a student sample. J Clin Psychol 2000;56:545-51.

[29] Osman A, Breitenstein JL, Barrios FX, et al. The Fear of Pain Questionnaire-III: further reliability and validity with nonclinical samples. J Behav Med 2002;25:155-73.

[30] Symonds TL, Burton AK, Tillotson KM, Main CJ. Absence resulting from low back trouble can be reduced by psychosocial intervention at the work place. Spine 1995;20:2738-45.

[31] Freburger JK, Holmes GM, Agans RP, et al. The rising prevalence of chronic low back pain. Arch Intern Med 2009;169:251-8.

[32] Deyo RA, Mirza SK, Martin BI. Back pain prevalence and visit rates: estimates from U.S. national surveys, 2002. Spine 2006;31: 2724-7.

[33] Deyo RA, Mirza SK, Turner JA, Martin BI. Overtreating chronic back pain: time to back off? J Am Board Fam Med 2009;22: $62-8$.

[34] Carragee EJ, Cohen SP. Lifetime asymptomatic for back pain: the validity of self-report measures in soldiers. Spine 2009;34:978-83.
[35] Fritz JM, Cleland JA, Brennan GP. Does adherence to the guideline recommendation for active treatments improve the quality of care for patients with acute low back pain delivered by physical therapists? Med Care 2007;45:973-80.

[36] Ramsey S, Willke R, Briggs A, et al. Good research practices for cost-effectiveness analysis alongside clinical trials: the ISPOR RCT-CEA Task Force report. Value Health 2005;8:521-33.

[37] Armed Forces Health Surveillance Center. Ambulatory visits among members of the active component, U.S. Armed Forces, 2009. MSMR 2010;17.

[38] Morasco BJ, Duckart JP, Carr TP, et al. Clinical characteristics of veterans prescribed high doses of opioid medications for chronic noncancer pain. Pain 2010;151:625-32.

[39] National Priorities Project - Military Recruitment 2010. National Priorities Project. Available at: http://nationalpriorities.org/publications/ 2011/military-recruitment-2010/. Accessed January 19, 2012.

[40] Hill JC, Whitehurst DGT, Lewis M, et al. Comparison of stratified primary care management for low back pain with current best practice (STarT Back): a randomised controlled trial. Lancet 2011;378:1560-71. 